\section{A segmentação arterial do baço da capivara (Hydrochoerus hydrochoeris)*}

CORRESPONDENCE TO:

Maria Angelica Miglino

Depertamento de Cirurgia

Faculdade de Medicina

Veterinária e Zootecnia da USP

Av. Prof. Dr. Onlando Marques

de Paiva, 87

Cidado Universitária Armando

Salles de Oliveira 05508-900.

Sao Paub - SP - Brasil

Q-mail:miglino ousp.br

1. Fundação de Ensino Superior

Óctavio Baslos, São João da Boa

Vista, São Paulo, SP

2. Departamento de Cirurgia

Faculdade de Medicina Velerinánia

- Zoolocnia da USP - SP.

3. Universidade Santo Amaro,

Santo Amaro. SP e Escola

Paulista de Medicina, São Paulo.

SP

4. Departamento de Apoio.

Producăo e Saúde Animal

Faculdade de Odontologia da

UNESP. Aracatuba, St

\title{
RESUMO
}

Os autores estudaram, através do método da dissecação, a ramificação da artéria esplênica no baço de 28 capivaras (Hydrochoerus hydrochoeris), jovens e adultas, machos e fêmeas. O número de segmentos arteriais da capivara varia de 5 a 16, mais freqüentemente 10. O número de lobos no baço varia de 3 a 7 . Existe uma correlação entre lobos e segmentos. Um baço acessório aparece em $21,4 \%$ dos casos.

UNITERMOS: Segmento; Artérias; Baço; Capivaras

\section{INTRODUÇÃO}

$\mathrm{O}$ grande crescimento da criação c da exploração zootécnica e racional de Animais Silvestres, como fonte alternativa na alimentação humana. em especial da criação de capivara (Hydrochoerus hudrochoeris), o maior roedor encontrado na América do Sul, levou-nos a escolher este tema para a realização deste trabalho.

\section{MATERIAL, E MÉTODO}

Para a realização desta pesquisa utilizamos 28 baços de capivara (Hydrochoerus hydrochoeris), jovens e adultos de ambos os sexos.

O processamento de abate era feito segundo as técnicas utilizadas para tal fim. A pós a cvisceração, os baços foram coletados e em seguida acondicionados em sacos plásticos resfriados e depois transportados para o laboratório de $\Lambda$ natomia da Faculdade de Medicina Veterinária Octavio Bastos. onde foram injetados com solução aquosa de formol a $10 \%$ e acondicionados em cubas contendo solução aquosa de formol a $10 \%$ por 48 horas.

Após a fixação, os órgàos tiveram a cápsula da face visceral parcialmente retirada e seus parênquimas dissecados, sob lupa, a fïm de que se visualizassem os vasos intra-esplênicos.

\section{RESULTADOS}

Os resultados da dissecação, referentes à distribuiçào da artéria esplênica em 28 baços de capivaras (Hydrochoerus hydrochocris) jovens e adultas, mostraram vários aspectos relativos à aparência externa do baço, à identificação de segmentos, à presença do esboço do baço acessório, à ocorrência de anastomoses entre as ramificações arteriais e às correlaçōes existentes entre lobos e segmentos (Figs. 1, 2, 8 e 11 ).

Deste modo, organizamos a descrição deste capítulo de acordo com os seguintes itens:

1. Morfologia externa do baço

2. Identificação de segmentos

3. Baço acessório

4. Anastomoses

5. Correlaçòes entre lobos ce segmentos

\section{Morfologia externa do baço}

Em 4 casos dos 28 examinados ( $14.3 \%$ ), o baço da capivara apresenta o formato externo semclhante àuele encontrado nos eqüideos, ou seja, ligeiramente triangular, sem resquicio de fissuras. sendo mais largo na porção relativa ao seu hilo, onde penetra a artéria esplênica, diminuindo gradativamente esta largura à medida que a artéria esplênica o percorria e emitia ramos endereçados ac seu parênquima.

Nos demais 24 casos $(85,7 \%)$, o baço apresentou formatc. geral semelhante ao descrito anteriormente ou seja ligeiramente triangular, sendo mais largo na região hilar. Entretanto, apareceram 

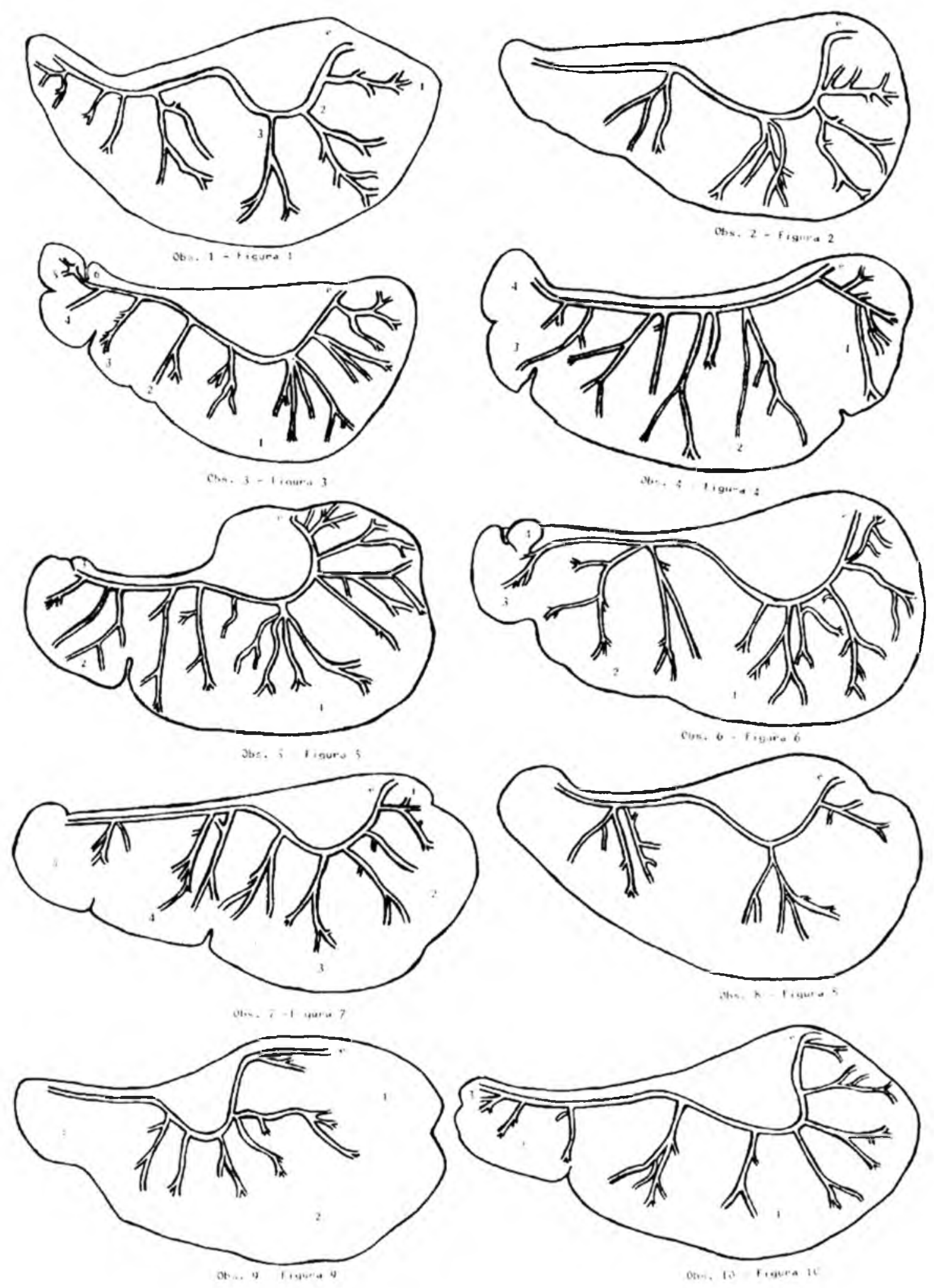

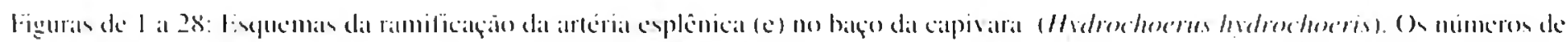

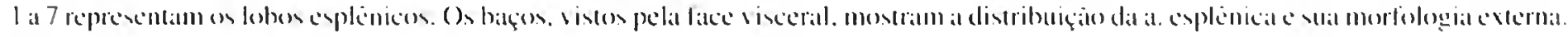



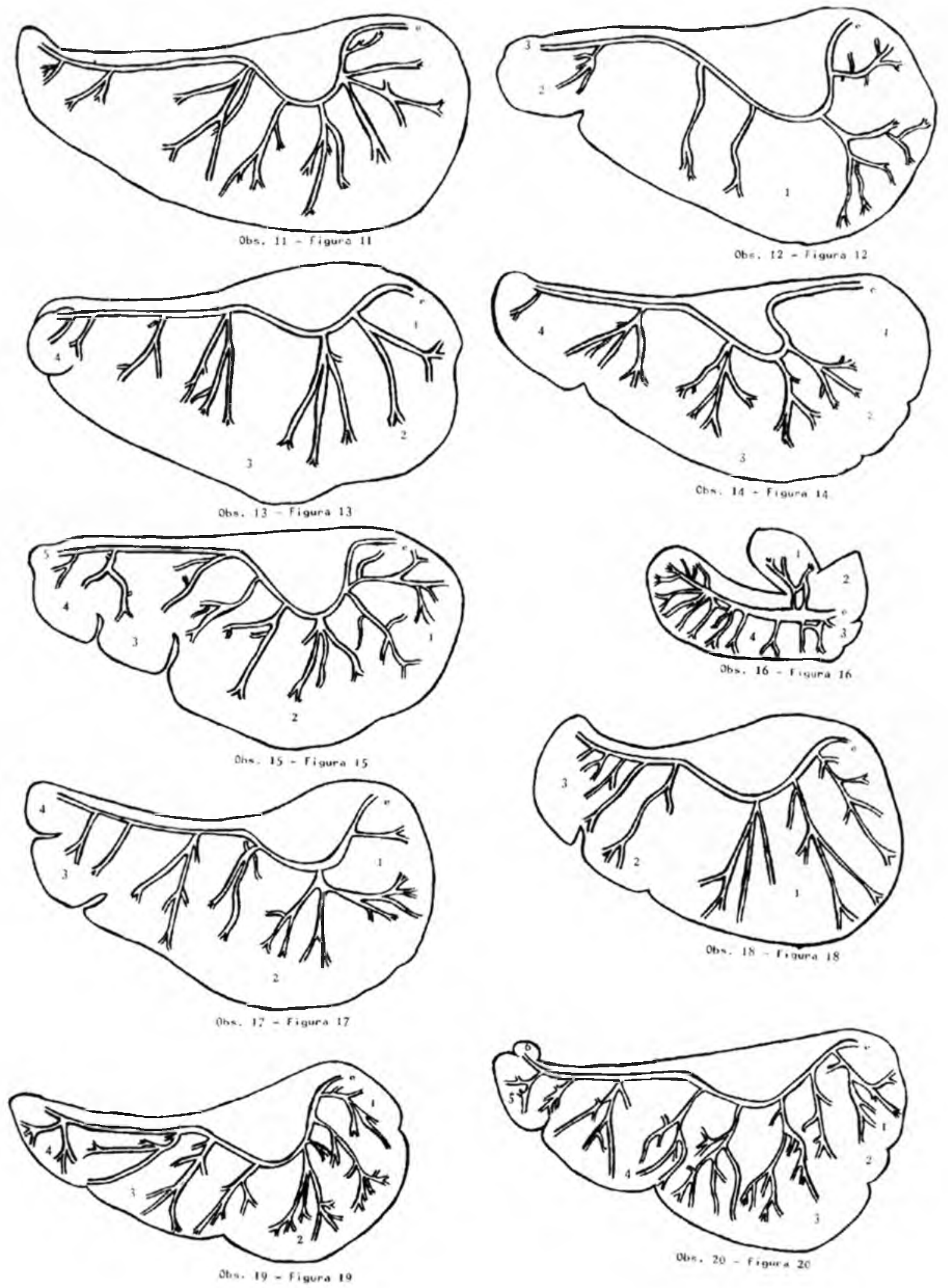

Fïguras de I a 28: Esquemas da ramificação da artéria esplênica (e) no baço da capivara (Hydrochoerus hydrochoeris). Os números de I a 7 representam os lobos esplênicos. Os baços, vistos pela face visceral. mostram a distribuição da a. esplênica e sua morfologia externa. 

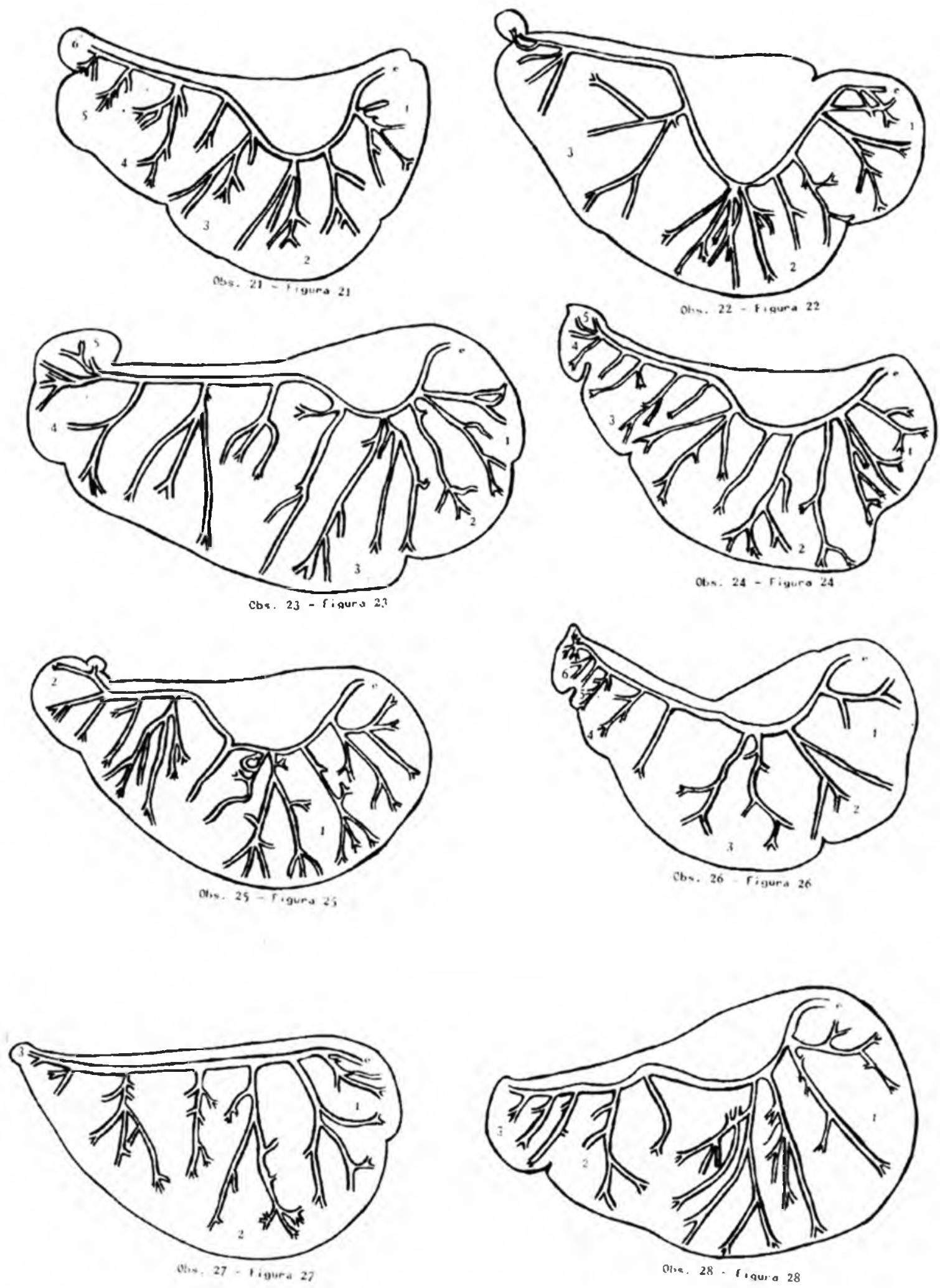

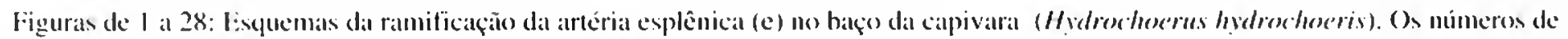

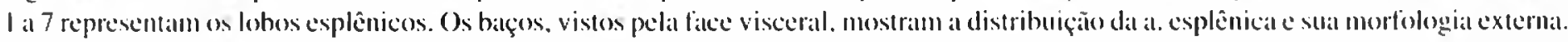




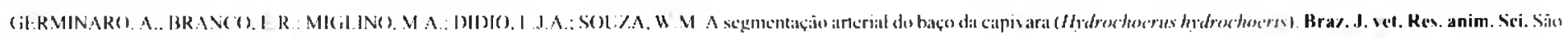

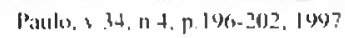

no parēncuima. especialmente nas margens ventral e caudal. algumas lissuras (fïg. 3) as quais denunciaram a presença de lobos esplénicos, os quais serajo descritos a seguir.

I:m 8 dos 24 casos (28.6\%). o baço da capivara mostrou fissuras que dividiram o orgaio em 4 lobos (Fig. 4. 6, 13, 14, 16. 17. 19 e 22). Em outras 8 capivaras $(28.6 \%)$ as lissuras dividiam o baço em 3 lobos.

Iim 3 das preparaçós ( $10.7 \%$ ), o baço da capivara dividia-se en 5 lobos. I:m outras 3 , das 24 peças $(10,7 \%)$, o baço mostrava 6 lobos.

Num úmico caso isolado $(3,6 \%)$ o baço da capivara aprescntava 7 lobos.

\section{Identificação dos segmentos}

Fin todos os baços examinados identificamos segmentos arleriais anátomo-cirurgicos.

Em 9 animais dos 28 examinados $(32.11 \%)$ encontramos 9 segmentos arteriais: em 5 baços $(17,9 \%$ ) identificamos 10 segmentos arleriais: noutros 3 órgãos (10,7\%, obs. 9, 12 e 14), encontramos 6 segmentos arleriais.

Iim 2 casos $(7.1 \%)$ encontramos 8 segmentos arterials. Fim outros 2 cassos $(7.1 \%)$ achamos 7 segmentos arteriais.
Outros 2 casos $(7.1 \%)$ mostraram 5 segmentos arteriais.

Dois outros baços $(7,1 \%$ ) mostraram 11 segmentos arteriais. Nota-se que nestes dois casos ocorreram 4 anaslomoses entre os ramos da artéria esplênica. Ima anastomose ocorreu em um destes casos.

Iim 3 casos isolados $(10,7 \%)$. verificamos 12,13 e 16 segmentos arteriais. No último caso ocorreram tambem 3 anastomoses.

\section{Baços acessórios}

Eim 6 dos 28 baços cxaminados $(21.4 \%)$ encontramos um esboço de baço acessório, ou scja um lobo completanente separado do parênquima do órgão c que, na maioria das vezes (4 casos). correspondia a um. dois e Irếs segmentos individualizados.

\section{Anastomoses}

Foram obscrvadas 3 anaslomoses num únicocaso. tolali. ando 7 anastomoses de grande calibre em 28 baços examinados.

\section{Correlaçōes entre lobos e segmentos}

Nos 24 baços lobados procuramos correlacionar o numero de lobos e o número de segmentos anatomo-cirúrgicos, com vistas

Tabela 1

Número de segłmentos nos lobos I a VII. São Paulo, 1995.

\begin{tabular}{|c|c|c|c|c|c|c|c|}
\hline $\begin{array}{c}\text { Lobos } \\
\text { (número) }\end{array}$ & $\begin{array}{c}\text { (cranial) } \\
\text { I } \\
\end{array}$ & II & [II & IV & $\mathrm{V}$ & VI & $\begin{array}{c}\text { (caudal) } \\
\text { VII } \\
\end{array}$ \\
\hline 3 (Obs. 5) & 09 & - & - & 03 & - & - & 01 \\
\hline 3 (Obs. 9) & 01 & - & - & 04 & - & - & 01 \\
\hline $3($ Obs. 10$)$ & 06 & - & - & 03 & - & - & 01 \\
\hline 3 (Obs. 12) & 04 & - & - & 01 & - & - & 01 \\
\hline 3 (Obs. 18) & 03 & 一 & - & 02 & - & - & 04 \\
\hline 3 (Obs. 25) & 07 & - & - & 03 & - & - & - \\
\hline 3 (Obs. 27) & 01 & - & - & 06 & - & - & 01 \\
\hline 3 (Obs. 28) & 03 & - & - & 02 & - & - & 04 \\
\hline 4 (Obs. 4) & 01 & 05 & - & - & - & 02 & 01 \\
\hline 4 (Obs. 6) & 06 & 02 & - & - & - & 02 & \\
\hline 4 (Obs. 13) & 01 & 01 & - & - & - & 02 & 03 \\
\hline 4 (Obs. 14) & - & 01 & - & - & - & 02 & 02 \\
\hline 4 (Obs. 16) & 02 & - & - & 一- & - & 01 & 12 \\
\hline $4($ Obs. 17$)$ & 01 & 02 & - & - & - & 02 & 01 \\
\hline 4 (Obs. 19) & 01 & 02 & - & - & - & 03 & 03 \\
\hline $4($ Obs. 22$)$ & 04 & 04 & - & - & - & 02 & 02 \\
\hline 5 (Obs. 7 ) & 01 & 04 & - & 02 & - & 02 & 01 \\
\hline 5(Obs. 15) & 02 & 03 & - & 02 & - & 01 & 01 \\
\hline 5 (Obs. 23$)$ & 01 & 02 & - & 06 & - & 01 & 01 \\
\hline $5($ Obs. 24$)$ & 02 & 04 & - & 04 & - & 02 & 01 \\
\hline $6($ Obs. 3$)$ & 04 & 01 & 01 & - & 01 & 01 & - \\
\hline $6($ Obs. 20$)$ & 01 & 01 & 02 & - & 02 & 02 & 01 \\
\hline $6($ Obs. 21$)$ & 01 & 02 & 01 & - & 02 & 01 & 02 \\
\hline 7 (Obs. 26) & 01 & 01 & 03 & 02 & 01 & 02 & - \\
\hline
\end{tabular}


a delerminar quantos segmentos existiam em cada lobo e se um lobo correspondia a um segmento.

Nos 8 casos $(28.6 \%)$ que mostraram + lobos, encontramos o) seguinte comprtamento:

A Tab. I mostra as correlaçoces entre o número de lobos esplénicos (de 3 a 7 ) e o número de segmentos antílomo-cirúrgicos existentes em cada lobo.

Assim, consideramos o numero miximo de fobos sencontrados (7) e denominamos cada um deles de acordo com o ponto de penetração da artéria esplênica (hilo esplénico). gue percorre o órgào no sentido crânio-caudal.

Destc modo temos:

Lobos: I (cranial), II, III, IV, V, VI e VII (caudal).

\section{COMENTÁRIOS}

$\Lambda$ identuficaçào de segmentos dos mais diversos órgãos. descrita inicialmente por Divos, apud Huu" (1938), paraos pulmòes. - estabeleceu uma nova fonte de investigatça cientilica para acpueles que se interessam em dirigir suas pesquisals a anatomia aplicadda.

Basciado no conceito de segmentação esplênica, Volkmannn 27 (192.3) jai assinalaval a possibilidade de se farer resseçoes parciais do baço, remoçóes de cisto ou mesmo implante de outros órgàos. sem ocorrência de grandes hemorragias.

$\Lambda$ divisào da arléria esplénica, mesmo antes de penetrar no baço, fato que näo ocorre na capivara (Mydrochecrass hydrochecris). dá origem a segmentos arteriais os quais são contados em números diversos para as diferentes especies.

A bem da verdade, relativamente ao baço e à circulação esplênica de Roedores, somente Braithwaite; Adams $^{3}$ (1957), estudando ratos vivos, relataram alguns aspectos da circulaçiono esplenica, nos quais verificaram a drenagem venosa dos compartimentos esplênicos, denominando-os segmentos esplénicos.

Na capivara, o maior rocdor do mundo, foram identiticados segmentos arteriais em todos os baços examinados e o numero destes segmentos varion de 5 a 16 , mostrando em média 10 segmentos por órgào.

liste resultado não pode ser comparado aos dados descritos has demais especies. como é o caso do proprio homem, pois a maioria dos autores tais como (ruveilhier (18.37): Debierret

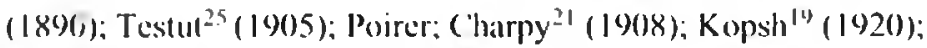
(asiraghit (1969): Woodbournce ${ }^{2 x}(1978)$ : Esperançat-Pina ${ }^{12}$ (1979); (unningham ${ }^{7}$ (1949); Testut: Latarjet ${ }^{25}$ (1952): $\mathrm{Huu}^{17}$ (1953); Katritsis el al. ${ }^{\times}(1982)$ e Rouviére: Delmas ${ }^{23}$ (1985) refere-se a presença de determinados números de ramos arteriais, sem descrever entretanto o número de segmentos encontrados no baço. (lausen ${ }^{6}$ (1958) observou para o homem, $\mathrm{cm} 80 \%$ dos baços estudados, a presença de apenas 2 segmentos arleriais, determinados por um plano avascular intersegmentar, perpendicular ao eixo principal do baçoco.

Raciocinio semelhante poder-se-ia considerar para algumas outras espécies como é o calso do gamba Silva ${ }^{24}(1992)$, do ovino deslanado (Bombonato ef al. $\left.{ }^{2}, 1989\right)$ ). do galo (l'aujour' $\left.{ }^{3}, 1948\right)$ o dos carnivoros e suinos (Zimmerl ${ }^{31}$. 1930).

Outros autores ao manifestarem-se sobre a presença de segmentos arteriais esplénicos no homem, foram (iupta ef al. ${ }^{16}$ (1976), os quais encontraram, em 84\% dos casos estudados, 2 segmentos (superior e inferior) e em 16\% $16 \%$ segmentos (superior, médio e interior). De forma semelhante. Acettil $1(1981)$ baseou-se no estudo radiológico para determinar 3 ou 4 segmentos esplénicos c Mandarim-de-Lacerda ("t al. ${ }^{20}$ (1983). estudando nalimortos. observaram que $40 \%$ dos baços apresentavam 2 segmentos, $44 \%$ mostravam 3 segmentos c 16 " " apresentavam-se sem padrào segmentar detinido. Em outral oportunidade. Mandarim-de-I acerda ("I al. 2" (1983). estudando moldes de baços de neonates, observaram que a divisĩo segmentar desses baços cra similar ao do baço adulto: com 2 segmentos (68,2\%), 3 segmentos $(10,6 \%$ c) 4 segmentos $(4,5 \%)$.

Garciat-1'orrero: Lemes ${ }^{14}$ ( 1988 ) al irmam-nos que segmentos são territorios correspondentes a ambes os ramos primários da artéria esplénica (segmento primário) e a artéria polar (segmento polar). Em $92.82 \%$ dos casios há 2 segmentos primários e em $7.18 \%$ hai 3 segmentos primairios; associados a estes. em 29,82\% hai um segmento polar superior, em $44.75^{\circ} \mathrm{n}$, um segmento polar inferior e cm 10,49\%, ambos os segmentos superiores

No concernente a segmentaçaio do baço no homem e nos animais domesticos. Dixon et al. ${ }^{11}$ (1980) estudaram lo baços de cães e 10 baços humanos. Planos relativamente vasculares foram evidenciados entre segmentos.

Relativamente ao aparecimento de anastomoses. Huul? (1953) alirma que, has artírias que separam o baço em 2 kerritórios arteriais superpostos, há evidencia, não rara, de anastomoses importantes entre os diversos territórios arteriais. classificamente considerados como absolutamente independentes.

Anastomoses arteriais tambem são citadas por Zapalláa" (1959), que se refere a um círculo anastomótico $(1.3 \%)$ e anastomoses extra-hilares $(4.8 \%)$; por Esperança-Pinal2 $(1979)$. que se refere à insuficiência funcional em esplenectomiass parciais: por Dixon et al. " (1980) em caes; por Rays et al. ${ }^{22}(1982) \mathrm{em}$ buffalos; por Mandarim-de-Lacerda on al..$^{211}(1983)$ em crianças natimortas, e por (iarcia-Porrero; Lemes't (1988) no homem adulto.

As 7 anastomoses que encontramos na capivara em 3 casos $(10.7 \%)$ já foram identificadas e disculidas em outras especies. Interessante é considerar que em 2 casos apareceram 3 anastomoses em cada animal, sendo que estes apresentavam idade inferior ais outras capivaras.

Analisando agora a forma do baço e suas event thais lobaçòes. verificamos que na capivara apareceram em $85,7 \%$ fissuras nass margens ventral e caudal do orgaio, dividindo-o em lobos. () número de lobos esplénicos variou de 3 a 7 . tendo sido denominados I, II, III, IV V, VI e VII no sentido crânio-ciatudal

$\Lambda$ pesar de considerarmos as diferentes espécies e as particalaridades morfologicals do baço de cada espécie, somente Dixon e’ al. ${ }^{11}$ (1980), estudando baço de caies, e Dawson el al. ${ }^{x}(1985)$. trabalhando com baços humanos, referem-se a presençal de lobos esplénicos. os quais sào contados no hemem em número de $2(71 \%)$ $\mathrm{c}+(29 \%)$ lobos.

As correlaçós por nós consideradas entre lobos e segmentos são igualmente mencionadals por Dixon " al." (1980) que. diferentemente dos nossos resultados, atïrmam que a lobação externa e a distribuição arterial segmentar foram coincidentes. 


\section{CONCIUSOEES}

Do yue acabames de expor podemos concluir que:

I. () baço da capisara (hidrochocras hadrechoctis) apresenta formato externo semellante alo encontrado nos eqüideos. ou seja. ligeiramente triangular. mais largo no seu hilo (cramialmente) o mais cistreito cialudalmente.

2. Val matoria dos calsos apareceram fissurass nas margens ventral e caudal do ingaio dividindo-o en lobos.

3. (1)úmero de lobos esplentecos varionde 3 a 7 , sendo denominados I. II. III. IV. V. VI e V'II no sentido cränio-caltudal.
4. Foram encontrades segmentos anatomo-cirúrgicos em lodes os casos. O numero de segementos antomo-cirúrgicos dal capivara varrou de 5 a 16 . sendo em média 10 segmentos por baço.

5. Lim 21.4\% dos calsos apareceram esthoços de baços alcessorios. completamente separados do parenguima do órgào, é que correspondiam a um, dois e tris segmentos individualizados.

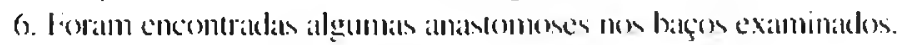

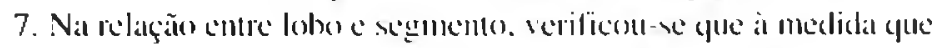
aumenta o nuimero de lobous. hai luma lendéncial de cadat lobo

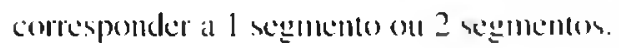

\section{SUMMARY}

The authors studied the branching of the splenic artery in the spleen of 28 capybaras (Hydrochoerus hydrochoeris), youngers and adults, males and females. The number of arterial segments of the capybara spleen varies from 5 to 16 , more freq ientely 10. Number of the lobes of the spleen varies from 3 to 7 . There are a correlation between lhe lobes and segments. One acessory spleen appears in $21.4 \%$ of the case.

\section{UNITIRMS: Segment, Arteries, Spleen, Capybara}

\section{RI:FIERENCIAS BIBLIOCIRÁFICAS}

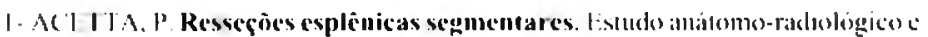

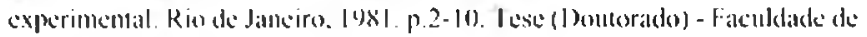

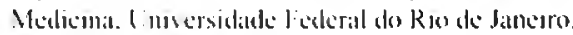

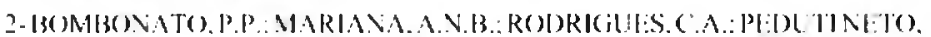
I. Splenic arterial vasculariation in wooless sheep In: ILDI R ATIVL

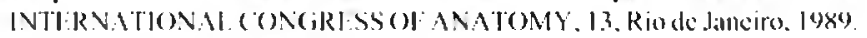

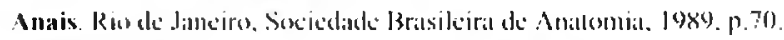

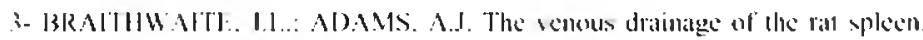
Journal of Allatum! . 91. 11.1. p.352-7. 195?.

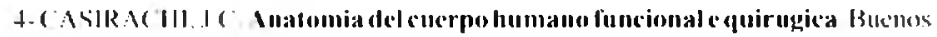
Airs. II Aknew. 1969. 1.4. p.160x-74.

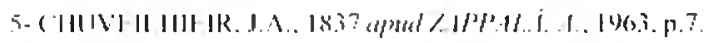

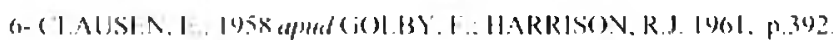

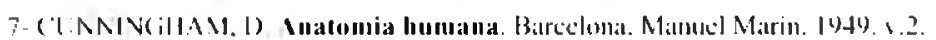
p. $)(12-4$

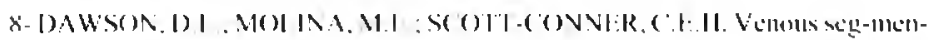

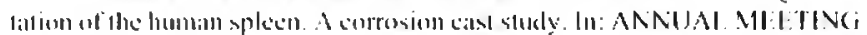

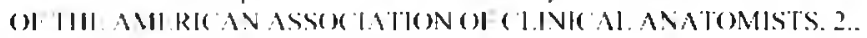

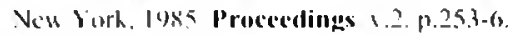

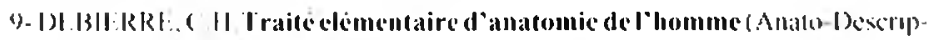

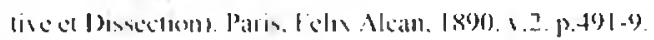

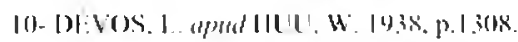

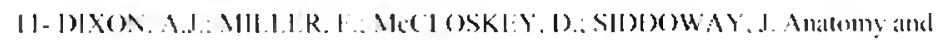

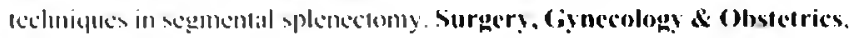
1.150. $1.1 .0 .516-20.198010$

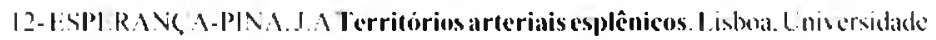

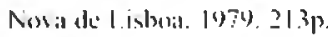

1:- I AlIOU R. R. Contribuition l'anatomic du sisteme arterial du chat. I yon.

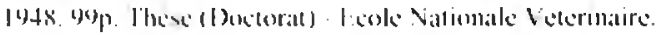

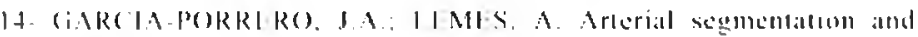

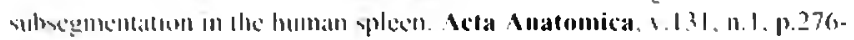
Sᄂ, loks

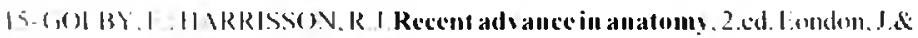
A. ( hurchill. $\mid 9(1)$ p. pis?

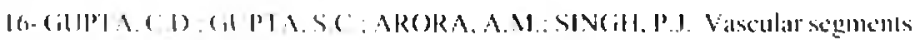

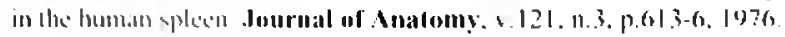

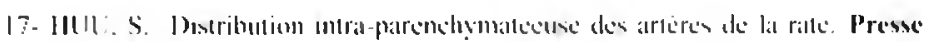
Medicale. s.61. It. I. p.1.308-9.1953.

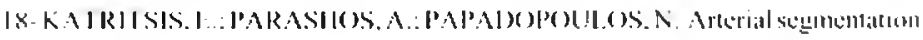
of the human splecen by post-murlem angiengrams and corrositm-ciasts. J.

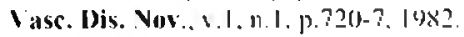

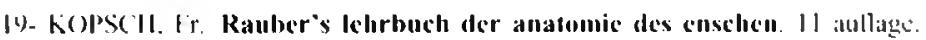
Aheilung. Lingewede. 1920. p. I:-4.

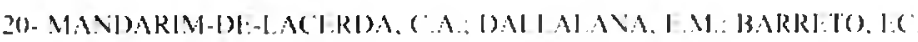

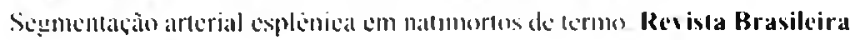
de (irurgia. 1.71.11.1. p.37-19.195:

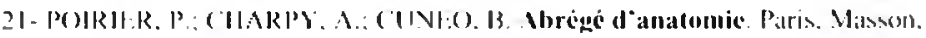

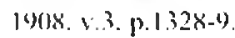

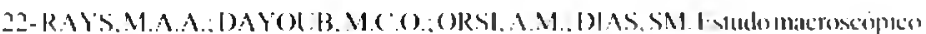

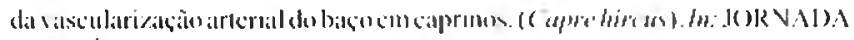

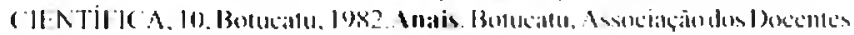
de Bulucialu L:NI:SP.

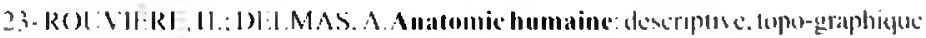

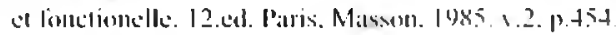

24- SIl V. Ir. I' C Istudo da ramilicaçäo arterial do baço de gambá o Dide'lphis

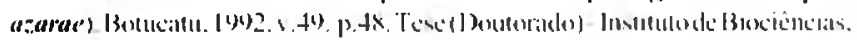

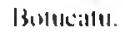

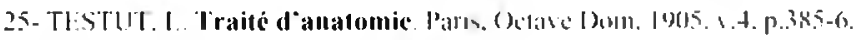

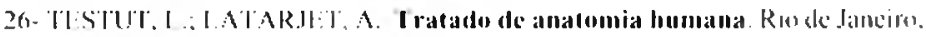
Silsial. |452 p.755-63|.

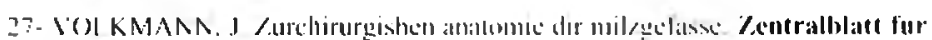
chirurgic. $4.50,1,1, p .436-8,192$.

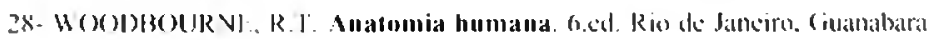
Kingaan. 197א. pr.323.

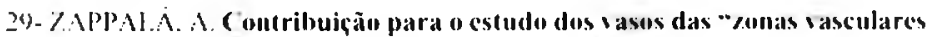

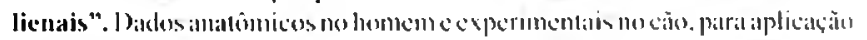

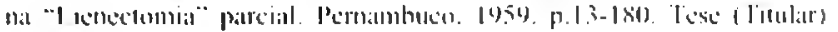
I aldukdadk de Medicinat. Universidlade de Pernilushuco.

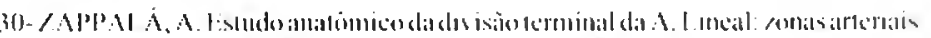
do balco. Anais da l aculdade de Medicina da l niversidade do Recife, 1.23. n. I. p.7-6.2. 16003.

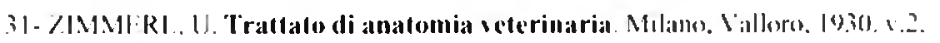
p. 154 .

Kecebido para publicação: $18 / 01 / 96$ Aprovado para publicação: 17/06/97 